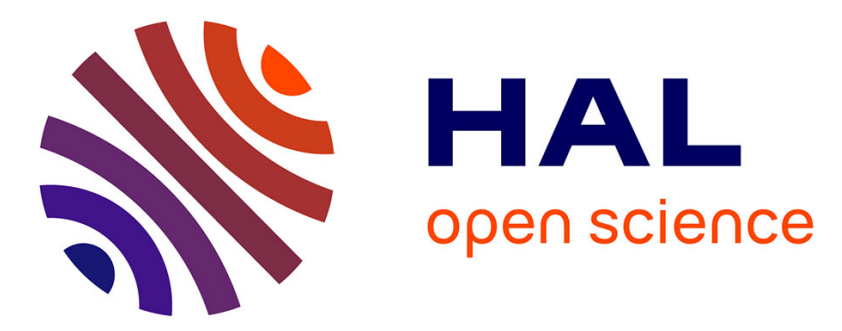

\title{
Least cost path analysis for urban greenways planning: a test with moths and birds across two habitats and two cities.
}

\author{
Manon Balbi, Solene Croci, Eric Petit, Alain Butet, Romain Georges, Luc \\ Madec, Jean-pierre Caudal, Aude Ernoult
}

\section{To cite this version:}

Manon Balbi, Solene Croci, Eric Petit, Alain Butet, Romain Georges, et al.. Least cost path analysis for urban greenways planning: a test with moths and birds across two habitats and two cities.. Journal of Applied Ecology, 2021, 58 (3), pp.632-643. 10.1111/1365-2664.13800 . hal-02996213

\section{HAL Id: hal-02996213 \\ https://hal.science/hal-02996213}

Submitted on 5 Feb 2021

HAL is a multi-disciplinary open access archive for the deposit and dissemination of scientific research documents, whether they are published or not. The documents may come from teaching and research institutions in France or abroad, or from public or private research centers.
L'archive ouverte pluridisciplinaire HAL, est destinée au dépôt et à la diffusion de documents scientifiques de niveau recherche, publiés ou non, émanant des établissements d'enseignement et de recherche français ou étrangers, des laboratoires publics ou privés. 


\title{
Journal of Applied Ecology
}

DR AUDE ERNOULT (Orcid ID : 0000-0003-4654-0072)

Article type : Research Article

Editor - Juan Corley

Least-cost path analysis for urban greenways planning: a test with moths and birds across two habitats and two cities

Manon Balbi ${ }^{1}$, Solène Croci ${ }^{2}$, Eric J. Petit ${ }^{3}$, Alain Butet ${ }^{1}$, Romain Georges ${ }^{1}$, Luc Madec ${ }^{1}$, Jean-Pierre Caudal $^{1}$, Aude Ernoult ${ }^{1, *}$

1: UMR CNRS ECOBIO, Université de Rennes 1, Avenue du Général Leclerc, 35042 Rennes Cedex, France

2: CNRS, Université Rennes 2, UMR 6554 LETG, Place du Recteur Henri Le Moal, 35043 Rennes Cedex, France

${ }^{3}$ : ESE, Ecology and Ecosystem Health, Agrocampus Ouest, INRAE, 35042 Rennes, France

*: corresponding author: aude.ernoult@ univ-rennes1.fr

\begin{abstract}
1. One of the major planning tools to respond to urban landscape fragmentation is the development of ecological corridors, i.e. interconnected networks of urban green and blue
\end{abstract}


spaces. Least-cost paths (LCP) appear to be an easy and appropriate resistance-based modeling method to respond to urban planners' needs. However, the ecological validation of urban corridors using LCP is rarely performed and needs to be generalized to different species, habitats and cities.

2. We developed an experimental design to test the efficiency of LCP predictions to detect highly connecting landscape contexts that facilitate individual movements compared to movements in less connecting landscape contexts. We deliberately assigned LCP analysis parameters based on the scientific literature and expert knowledge to test a method potentially easy to use for urban stakeholders. To extend the validation, we applied our LCP model to two biological taxa with different habitat requirements: grassland-dwelling moths and forestdwelling passerines, and to two medium-sized cities.

3. We used mark-release-recapture (MRR) methods for moths and playback recall protocols for passerines to compare the patterns of individual movement between two contrasted connectivity contexts determined by the presence and absence of modelled LCPs. MRR protocol estimated movement rates between herbaceous patches and the two contrasted connectivity contexts. Playback recall protocol consisted in attracting individuals from wooded patches to the two contrasted connectivity contexts. A movement was considered facilitated, when displacement was rapidly engaged and individuals moved a long distance from their wooded patch.

4. Moth and passerine movement patterns differed between the two connectivity contexts: moth recapture rates were higher in highly connecting contexts than in less connecting contexts. For passerine birds, responses to playback recalls were faster and movement distance longer in highly connecting contexts. All results support the hypothesis that both taxa were more prone to move in corridors modeled by LCP. 
5. Synthesis and applications: The convergence of the results for different biological models and across cities strengthens the relevance of LCP analysis for planning urban greenways and provides guidelines for landscape planners in the development of these corridors to favor the movement and survival of multiple urban species.

Keywords: birds, fragmentation, green infrastructure, herbaceous corridor, least-cost paths, moths, resistance-based model, urban landscape, wooded corridor. 


\section{Introduction}

Urbanization is a major threat to biodiversity (Grimm et al., 2008). It is mainly caused by the transformation of vegetated soils into impervious surfaces and strong habitat fragmentation, i.e. an increase of habitat patch isolation and a decrease of habitat patch amount (Forman, 2014; Merckx et al., 2018). Maintaining urban biodiversity is thus of major importance because it contributes to biodiversity conservation (Aronson et al., 2017) and provides multiple ecosystem services, including urban citizens' wellbeing and recreation, climate and air quality buffering (Bowler, Buyung-Ali, Knight, \& Pullin, 2010). The development of ecological corridors, i.e. networks of urban green spaces and blue infrastructures (Aronson et al., 2017; Gilbert-Norton, Wilson, Stevens, \& Beard, 2010) is one way to reduce the negative effects of habitat patch isolation on biodiversity. Indeed, research on landscape ecology attests the importance of restoring landscape functional connectivity, defined as the degree to which the landscape facilitates or impedes movement among resource patches (Taylor, Fahrig, Henein, \& Merriam, 1993). According to this definition, landscape connectivity promotes different types of movements expressed at different spatio-temporal scales, both dispersal and movements for foraging activity or territorial defence (LaPoint, Balkenhol, Hale, Sadler, \& van der Ree, 2015; Abrahms et al., 2017). The development of green infrastructures has become one of the main targets of environmental planning in Europe (France: Grenelle Environment, 2010, UK: DCLG 2012) and in the USA (EPA 2014). However, urban planners encounter difficulties accessing easy and appropriate methods and models to plan ecological corridors that really facilitate the movement of organisms in cityscapes.

Resistance-based models are usually used to model functional connectivity, and to identify possible ecological corridors (Fagan and Calabrese, 2006). These models are mainly based on landscape resistance values that reflect the energetic cost for an individual to move, 
its willingness to move, and/or the risk of moving across each type of land cover (Zeller, McGarigal, \& Whiteley, 2012). These models identify areas where movements are facilitated and, in contrast, areas where land cover impedes movements (Braaker et al., 2014). Among the available connectivity models (Circuit theory: McRae, Dickson, Keitt, \& Shah, 2008; Individual-based models: Palmer, Coulon, \& Travis, 2011; Least-cost path: Adriaensen et al., 2003; Sawyer, Epps, \& Brashares, 2011) least-cost path (LCP) analysis appears to be the easiest method to implement and compute (Coulon et al., 2015), making it a good candidate for transfer to urban planners. Predicted corridors, however, planned by LCP or other modeling tools, need to be experimentally validated, which is too rarely performed (Abrahms et al., 2017; LaPoint et al., 2015). In a previous study, we helped fill this gap by showing that the movements of hedgehogs (Erinaceus europaeus) were facilitated in ecological corridors predicted using LCP analysis (Balbi et al., 2019). However, the efficiency of models in identifying urban corridors depends on their ability to predict connectivity for multiple biological taxa with different habitat requirements and dispersal capacities (Breckheimer et al., 2014). Indeed, for urban planners, it would not be effective to plan ecological corridors for just one species, especially in cities where the areas appointed as green infrastructures are spatially restricted. Inversely, from a biological point of view, it would be unrealistic to imagine that one type of ecological corridor would work for all the species present in an urban landscape. To reach an acceptable compromise, several prerequisites should be taken into account when validating the ability of connectivity models to respond to landscape planner needs. The first is to validate the models in different types of ecological corridors representative of urban green infrastructures (Breckheimer et al., 2014). Green infrastructures in cities fall into two main categories: herbaceous areas (open habitats) such as private or public lawns and grasslands; and wooded areas such as small woods or lines of trees. The second prerequisite is to confirm the efficiency of connectivity models for different species 
with different biological characteristics (Diniz, Machado, Bispo, \& De M. Júnior, 2018).

Many existing landscape connectivity studies are limited to one target species (Bond, Bradley, Kiffner, Morrison, \& Lee, 2017; Braaker et al., 2014; LaPoint et al., 2015) whereas urban planners need functional connectivity models for multiple taxa. Finally, the efficiency of connectivity models should be tested on a large panel of landscape configurations and structures (Richardson, Brady, Wang, \& Spear, 2016), and the independent landscape replicates need to be evaluated across different cities (Balbi et al., 2018; Richardson et al., 2016).

To test the efficiency of connectivity models, individual propensity or reluctance to move must be quantified (i.e. assessing functional connectivity) across different landscape features or configurations delineated by the model predictions (Bélisle, 2005; St Clair, 2003). Methods to quantify interactions between individual movements and the structure of the landscape vary with biological models (Knowlton \& Graham, 2010). Among the representatives of urban biodiversity, moths and birds are two interesting taxa from a landscape ecology point of view. First, although they are still relatively abundant in urban landscapes, their diversity is declining with increasing urbanization (Moths: Merckx \& Van Dyck, 2019; Bates et al., 2014 - Birds: Aronson et al., 2014). Second, their sensitivity to landscape connectivity differs among species (Murgui \& Hedblom, 2017; New, 2015). Finally, these two biological models can be used to test different habitat requirements: grassland-dwelling moths prefer to move through herbaceous habitats (Alison, Duffield, Morecroft, Marrs, \& Hodgson, 2017; Šumpich \& Konvička, 2012) whereas forest-dwelling birds avoid crossing open areas (Tremblay \& St Clair, 2011) and depend more on a continuous wooded area for nesting and foraging activities (Creegan \& Osborne, 2005; St Clair, 2003). To study landscape-dependent movement behaviors of birds, playback recall protocols are widely used. This experimental method standardizes individual motivation to 
move and has been used to estimate landscape resistance by testing matrix permeability (Castellón \& Sieving, 2006), quantifying connectivity (e.g. St-Louis et al., 2014), or extracting resistance values (Shimazaki et al., 2016). A movement is considered facilitated when displacement is rapidly engaged and individuals move a long distance (the energy cost and risk for individuals remaining weak). This experimental design is more robust when it is associated with replicated individual measurements that take inter-individual variability into account (Betts, Gutzwiller, Smith, Robinson, \& Hadley, 2015). Because of their size and ecology, moths are most often studied using mark-release-recapture (MRR) protocols (Merckx et al, 2009, 2010; Slade et al, 2013). This method, which estimates movement rates between two locations, can compare relative movement/mobility and provides data about dispersal capacity and potential dispersal success (Merckx et al., 2010; Turchin, 1998).

The objective of the present study was to test the efficiency of LCP analysis for urban planners, i.e. the ability of LCP model to predict effective corridors in urban contexts when configured with knowledge accessible by non-specialists. To reach this objective, we 1) parameterized LCP analysis (resistance coefficients) only on the basis of a literature review and expert knowledge, as urban planners would, and 2) tested the efficiency of the predicted corridors, comparing movements of organisms along or outside those predicted corridors. To extend our validation of LCPs as a tool that could help urban planners conserving urban biodiversity, we applied our LCP model to two taxa with different habitat requirements: grassland-dwelling moths and forest-dwelling passerines. The MRR for moths and playback recalls for birds were thus applied in two medium-sized European cities (Lens and Rennes). According to the theory of functional connectivity, we expected that movements in the corridors predicted by our LCP models would be facilitated compared to movements in areas outside those corridors, i.e. we expected higher recaptures rates in the modeled LCPs for 
moths, and shorter response times and longer movement distances in the modeled LCPs for birds.

\section{Materials and methods}

Study areas

To capture a wide gradient of urbanization and thereby enable the results to be generalized more broadly, the protocols were replicated in two medium-sized cities in France: Rennes $\left(48^{\circ} 06^{\prime} \mathrm{N}-1^{\circ} 40^{\prime} \mathrm{W}\right)$, located in the Zone Atelier Armorique, a long-term ecological research (LTER) site; and Lens $\left(50^{\circ} 42^{\prime} \mathrm{N}-2^{\circ} 82^{\prime} \mathrm{W}\right)$ (Fig. 1A). The study sites comprised 60 sq.km in Rennes, with 58\% artificialized surfaces and $41 \%$ urban green spaces, and 56 sq.km in Lens, with $49 \%$ artificialized surfaces and $50 \%$ urban green spaces (and 1\% water surfaces in each city). The two cities thus share almost the same proportion of vegetation and impervious surfaces. A high-resolution $(5 \times 5 \mathrm{~m})$ habitat map was produced for each agglomeration by combining GIS data from the National Geographic Institute of France (BD TOPO (c) IGN 2010) and a classification of Worldview II remote sensing data (Digitale Globe (c) 2011). The habitat map contained eight land cover classes: buildings, roads, highways, water bodies, railways, impervious surfaces (all other asphalt surfaces, e.g. parking lots, sidewalks), wooded areas, and herbaceous areas. Wooded land cover included trees, bushes, groves, and hedgerows. Herbaceous land cover encompassed grasslands, lawns, and ruderal areas.

\section{Biological models}

Moths as a biological model for herbaceous urban corridors 
Although they are less frequently studied than butterflies, moths account for $90 \%$ of Lepidoptera species diversity (New, 2004). Moth diversity is rapidly declining in many ecosystems and urban areas are no exception (Bates et al., 2014; Merckx \& Van Dyck, 2019). In cities, adults are mainly present in urban gardens where the vegetation structure is diverse, heterogeneous, and rich in micro-habitats (Bates et al., 2014). Adults' flight movements are mostly directed towards reproduction, i.e. mating and oviposition, and also the search of nectar food resources (Scoble, 1992). We studied macro-moths families and one micro-moth family (Cambridae) which have rather large body sizes (Fox et al., 2014; Macgregor, Evans, Fox \& Pocock, 2017) to test LCP predicted corridors using MRR protocols. MRR protocols can easily be used for macro-moths, which can be marked on their wings and can be captured in large numbers using light traps during their peak flight season. We excluded woodeddependent macro-moths species to test LCP built for herbaceous urban corridors (following Slade et al., 2013; Betzholtz, Pettersson, Ryrholm, Franzén, 2013).

Passerine songbirds as a biological model for wooded urban corridors The birds we studied were all forest-dwelling passerine species whose sensitivity to urban constraints varies (Croci, Butet \& Clergeau, 2008). Their movements are impacted by urban landscape structure: they avoid crossing roads and open areas (Tremblay \& St Clair, 2011) and they depend on forest edges and continuous wooded areas (Creegan \& Osborne, 2005; St Clair, 2003). The passerines were selected to account for (i) their abundance in cities; (ii) their capacity to respond to playback recalls (territorial songs during the reproduction period; Potts \& Lewis, 2014). We selected eight species, common in French cities (Croci et al., 2008): the Common chiffchaff (Phylloscopus collybita), the Short-toed treecreeper (Certhia brachydactyla), the Great tit (Parus major), the Eurasian blue tit (Cyanistes caeruleus), the Eurasian blackcap (Sylvia atricapilla), the Dunnock (Prunella modularis), the European robin (Erithacus rubecula), and the Eurasian wren (Troglodytes troglodytes). In our study, the 
movements of these eight bird species were tested via playback recalls to test LCP built for wooded habitats.

\section{Modeling corridors}

We used LCP models to predict corridors, i.e. areas of high-level of connectivity. For each biological model, this method requires: (i) selecting all source habitat patches, and (ii) building a map on which a resistance value is assigned to each pixel according to its land cover type. LCP analysis then consists of defining least-cost paths that link source habitat patches with one another, i.e. the paths that cumulate the lowest resistance value extracted from the resistance map (Adriaensen et al., 2003). The modeled LCPs are then considered to be the most efficient corridors in which movements of each taxa should be facilitated and be highly probable.

Habitat patches are defined as the favorable resting and foraging sites for the species under study (LaPoint, Gallery, Wikelski, \& Kays, 2013). For the moths, habitat patches were defined as continuous herbaceous areas $>2$ ha. This patch size was selected to ascertain that most species of the moth guild can be present in the source. They correspond to major urban parks, dominated by grass and rich vegetation structures (e.g. groves, scrubs, tall grasses or trees) that were estimated to be favorable as resting, foraging and egg-laying sites (Bates et al., 2014). For forest-dwelling passerines, habitat patches were defined as continuous wooded areas $>1$ ha, corresponding to small woods and groves, presumed to be favorable nesting sites for some nesting pairs of the eight selected bird species (e.g. Croci et al., 2008). The resistance values correspond to the facility with which an individual moves through each land cover class. Resistance maps were built by assigning resistance values to each land cover class (Zeller et al., 2012). To test if the method would be easy to use for urban stakeholders, 
we deliberately attributed resistance values from the scientific literature. After ranking land cover from the least to the most resistant, the resistance values were assigned (detailed in Appendix S6). To test the sensitivity of LCP analysis to landscape map resolution, resistance values on each resistance map (moths and birds) were weighted by the local context using a sliding-window method (using Chloé 2012, Boussard \& Baudry, 2014). The resistance value of each cell was weighted by the mean of the resistance value of the neighboring cells included in the sliding window (i.e. a circle with a specified diameter). Five weighted resistant maps were produced, each corresponding to a different sized sliding window: $15,25,35,55$, and $75 \mathrm{~m}$ in diameter. This range is consistent with the perceptual range of our biological models (for moths, we used butterflies as proxy: Pe'er, Saltz, Thulke \& Motro, 2004; Merckx \& Van Dyck, 2007; passerines: Evans, Kilpatrick, Hurlbert \& Marra, 2017).

LCPs were then modeled based on the five weighted resistance maps obtained for each taxon to link source habitat patches using ArcMap 10.3 (ESRI, USA) and Graphab (Foltête, Clauzel, \& Vuidel, 2012). Only LCPs modeled and superimposed on all the five resistance maps were considered as robust enough to be efficient corridors. The modeled LCP maps led to the identification of two landscape contexts that differed in connectivity levels: highly connecting contexts (HCC) that correspond to areas highly connecting to source habitat patches thanks to the presence of predicted corridors (i.e. where robust LCPs were modeled); less connecting contexts (LCC), which correspond to areas with no corridor (i.e. where no LCPs were modeled) (Moths: Fig. 1, Appendix S3-S7- Passerine birds: Fig. 1, Appendix S4-S8).

\section{Assessment of movement}

We checked LCP predictions by assessing the movement of moths and passerines in two contrasted connectivity contexts. 
Mark-release-recapture of macro-moths

The movement rate of moths in HCC and LCC was estimated using a mark-release-recapture (MRR) protocol. The dependent variable was the number of recaptured individuals (hereafter “number of recaptures") in HCC and LCC during an MRR session. The moth MRR experiments took place from June to August (peak flight season), in 2015 in Lens and in 2016 in Rennes. The MRR protocol consisted in marking all individuals trapped in the central habitat area on two consecutive nights, and then counting marked individuals recaptured in satellite areas during the two following nights. Six MRR spatial replicates (three in each city) were selected across urban areas (Fig. 1) and the MRR protocol was repeated three times in each replicate. Recaptured individuals were identified to species level. The MRR protocol is described in details in Appendices S1, S3 and S5.

Playback recalls of passerines

For passerines, we assessed the efficiency of LCP predictions using the response behavior of individuals to playback trials. The playback trials took place from April to May in 2015 in Lens and in 2016 in Rennes, from sunrise to $1 \mathrm{pm}$. The playback trial systems were composed of a "departure" area and two types of $200 \mathrm{~m}$ long adjacent transects. The first one was located in HCC (along predicted LCP), and the second one was located in LCC (Fig. 1). Playback calls were loud enough to dominate city sounds. Birds movements in LCC and HCC were visually tracked by close observers. Our dependent variables were 1) the "maximum distance" flown by an individual bird in each context and 2) the "response time" of an individual bird that responded positively to each playback trial. The response time was a proxy for the bird's motivation to move, combining the individual decision time and movement speed. A few negative responses were linked to the presence of another responding 
individual of the same species. We thus added a variable specifying whether another individual was present or absent to the maximum distance dataset. The playback recall protocol is described in details in Appendices S2 and S4.

\section{Statistical analyses}

We compared the numbers of moths recaptured (in each satellite area during an MRR session) between HCC and LCC. We gathered data from the two cities in a generalized linear mixed model. We used mixed models to capitalize on the power of the multiple connectivity contexts related to the same source habitat patch and study site replicates. The complete model used in model selection analysis linked the number of recaptures with the connectivity context (HCC and LCC), in interaction with cities (Lens and Rennes) as fixed effects and source habitat patch identification as random factor (with random intercept). Dealing with count data, the model was based on a Poisson error distribution and on the log link function. For passerines, we analyzed if the maximum distance reached, and the response time, differed between the two connectivity contexts (HCC vs LCC). We gathered data for the eight species and the two cities in linear mixed models. We used the linear mixed models to capitalize on the power of the individual paired design and study site replicates. The individual repeated measurements made in HCC and LCC allowed us to compare responses paired per individual and thus to control for inter-individual variations. Data concerning the maximum distance reached and the bird's response time were all square-root- transformed prior to analysis. The complete linear model explaining the maximum distance included all double interactions between the fixed effects: connectivity contexts (HCC and LCC), species, cities and "other individual". The random part of the model (with random intercept) nested "departure" area identification and individual identification. The complete linear model of the response time 
included the connectivity contexts as fixed effects in interaction with distance from the "departure" area, species and cities. The random part (with random intercept) nested “departure" area identification, individual identification, and trial relay identification. These complete models were used as inputs in model averaging analyses (Grueber, Nakagawa, Laws, \& Jamieson, 2011). We used the function dredge (R package MuMIn, Bartoń, 2020) to compute AICc and effect sizes on all submodels that could be built from our set of predictor variables for the different response variables (Grueber et al., 2011). We then performed model averaging analyses by extracting confidence intervals for effect sizes while retaining all models within a $\triangle \mathrm{AICc}$ of 4 from the best model (we obtained the same results when keeping only models within a $\triangle \mathrm{AICc}$ of 2). Variables that have a significant effect on our response variables are the variables for which the model averaged confidence interval excluded zero (Galipaud, Gillingham, David, \& Dechaume-Moncharmont, 2014). To look further into particular contrasts that involved the connectivity context effect, we used post-hoc pairwise comparisons among estimated weighted marginal means computed on the model that had the lowest AICc with the R-package and function 'emmeans' (Lenth, Singmann, Love, Buerkner, \& Herve, 2018). We adjusted p-values for these pot-hoc comparisons by controlling the false discovery rate (Benjamini \& Hochberg, 1995) with the R function p.adjust.

\section{Results}

Moths as indicator species of herbaceous corridors

We marked a total of 6098 individuals in the two cities (3372 in Rennes and 2726 in Lens).

These marked individuals belonged to 215 identified species (Appendix S9). Among the 
marked individuals, 61 were recaptured (77\% of them in HCC and 23\% LCC). Recaptured individuals belonged to 36 different species (32 species in HCC; 12 in LCC) such as $A$. exclamationis and S. lubricipeda, which were the most abundant (Appendix S10). Eight species were found both in HCC and LCC (for example A. exclamationis, C. elinguaria, $M$. abruptaria). The recapture rate in satellite areas (HCC and LCC combined) was $1 \%(0.79 \%$ in HCC and $0.21 \%$ in LCC). The number of recaptured individuals in each satellite area during an MRR session was on average 0.71 in $\mathrm{HCC}($ range $=0-4)$ and 0.23 in LCC (range $=0-2$ ) (Fig. 2). All models within a $\triangle \mathrm{AICc}$ of 4 from the best model, including the best one, included the connectivity context in the explanatory variables. Indeed, the number of recaptured moths was significantly higher in HCC than in LCC and this difference was similar in the two cities, as evidenced by $95 \%$ confidence intervals of effect sizes (Appendices S11 and S12).

Passerine birds as indicators of wooded corridors.

We conducted 830 trials from the border of 104 different "departure" areas, among which 551 elicited a positive response from a bird. We analyzed 213 individuals (80 in Lens and 133 in Rennes) that furnished 426 paired positive responses at the border of the "departure" area on the two successive days. The 213 individuals belonged to the following species: $70 P$. collybita, 31 P. major, 28 E. rubecula, 23 T. troglodytes, 21 S. atricapilla, 20 C. caeruleus, 13 P. modularis and 7 C. brachydactyla (Fig. 3). All models within a $\triangle$ AICc of 4 included the connectivity context, as well as the influence of another individual on the focal bird, species identities, and the interaction between the other individual and the species (Appendix S13). With all species combined, the maximum mean distance observed during playback trials was greater in HCC than in LCC (overall means $=84 \pm 82 \mathrm{~m}$ in HCC and $46 \pm 67 \mathrm{~m}$ in LCC) and 
this effect size was significant (Appendix S14). This result was consistent across all species (Fig. 3). However, these differences between HCC and LCC varied between species (the basic model averaging analysis shows that all species respond differently to the connectivity context). The post hoc pairwise comparison among the two connectivity contexts for each species showed that they were significant for the species P. collybita, C. brachydactyla, E. rubecula, P. major and S. atricapilla but not for T. troglodytes, C. caeruleus and $P$. modularis. Another significant interaction was detected between species and the presence of another individual (Appendix S14). Though all models analyzed kept the city factor as an explanatory variable (Appendix S13), there was no difference between the two cities in the maximal distance covered by birds (Appendix S14). As for the maximal distance covered, all models retained for the model averaging analysis of the response time of birds in the recall experiment kept all explanatory variables as single factors. In addition, all these models had in common the interaction between the connectivity context and the distance from the departure patch (Appendix S15). The response delay was indeed longer in LCC (90 sec +/- $60 \mathrm{sec})$ than in HCC (81 sec +/- $58 \mathrm{sec}$; Appendix S16). In a post-hoc analysis, the predicted response time was significantly longer in LCC than in HCC at only $50 \mathrm{~m}$ from the border of the "departure" area (Fig. 4). The predicted response time at $50 \mathrm{~m}$ was $102 \mathrm{sec}(\mathrm{SE}=7)$ in LCC and $80 \mathrm{sec}$ $(\mathrm{SE}=4)$ in HCC. We detected no difference in response time between the two contexts at the distances of 100, 150 and $200 \mathrm{~m}$. Above $50 \mathrm{~m}$, the response time in LCC decreased whereas it remained constant in HCC, leading to similar response times between the two connectivity contexts (Fig. 4). In addition, we detected a species effect that was limited to a difference between Cyanistes caeruleus and Certhia brachydactyla and no city effect (Appendix S16). The interaction between context and species (apart for a difference between the Blue tit and the Short-toed treecreeper) and the interaction between context and city were not significant. 


\section{Discussion}

The aim of this study was to assess LCP analysis predictions for use by urban planners by studying the movements of two biological taxa in contrasted connectivity contexts of two French cities. Two protocols based on experimental data provided different kinds of information on natural and induced movement behaviors in moths and birds, respectively. Moths and passerines movement patterns differed between the two connectivity contexts: moths recapture rates were higher in highly connecting contexts than in less connecting ones. For passerine birds, responses to playback recalls were faster and distance movements longer in highly connecting contexts. All results support the hypothesis that both taxa were more prone to move in corridors modeled by LCP than in other urban areas.

\section{Least-cost paths vs urban matrix}

Moths were four times more likely to be recaptured in HCC than in LCC. The effect size was particularly strong in this MRR experiment, allowing us to demonstrate a difference in the use of HCC and LCC even if the absolute number of recaptures was low (Turchin, 1998). This recapture rate (1\%, HCC and LCC combined) was however similar to those reported in other MMR studies if we excluded for these studies the number of recaptures in the original mark site (Slade et al, 2013; Merck \& Slade, 2014). Moreover, in an urban context, overall light pollution may compete with light traps which - combined with intense habitat fragmentation may reduce the recapture rate compared to that in more natural contexts (Frank, 2006). Importantly, this strong effect size was the same in the two cities, supporting that areas predicted by LCP analysis as belonging to ecological corridors do facilitate moth movements. Likewise, passerines traveled significantly longer distance in well-connected contexts $(80 \mathrm{~m}$ in $\mathrm{HCC}$ and $45 \mathrm{~m}$ in LCC) and responded more rapidly in HCC than in LCC at $50 \mathrm{~m}$ 
supporting the hypothesis that birds seem more prone to move in urban corridors modeled by LCP analysis. The absence of a difference in response time in HCC and LCC beyond $50 \mathrm{~m}$ suggested that territorial behavior movements are triggered more quickly in HCC than in LCC, but that this motivation to move, once initiated, is similar in the two contexts. Again, these results were robust across the two cities studied. Nevertheless, even if movements of both birds and moths were limited in LCC, many species were recorded moving in both HCC and LCC. The urban matrix thus seems to considerably slow down or reduce the probability of movement, but does not represent a barrier to movement (Tremblay \& St Clair, 2011). This urban matrix permeability, even if low, should be taking into account in connectivity models interpretations and in urban planning (Betts et al., 2015; Knowlton \& Graham, 2010).

\section{Generalization across species}

Very few studies have validated resistance-based models with movement data from different groups of species in the same landscapes (but see Breckheimer et al., 2014). In order to extend a previous similar work on a ground-dwelling mammal (Balbi et al., 2019), we chose to focus on species belonging to two other taxonomic groups - insects and birds - in the same urban landscapes. The moth and passerine experiments involved many species (40 moth species and 8 passerine species) that displayed rather similar behavioral responses to the predicted connectivity contexts: all moved more easily or more willingly in modeled LCP than in the urban matrix. This study extends the relevance of corridors modeled by LCP for only one species (see for example Abrahms et al., 2017; McClure, Hansen, \& Inman, 2016) to numerous species. However, our results also suggest that some species benefit more than others from urban corridors. For birds, there was a non-significant difference in the distance travelled between HCC and LCC in three species out of eight, even though the observed 
difference followed the same pattern as in the other species. Moreover, the distances travelled in the two contrasted connectivity contexts differed with the species. In the case of moths, of the 36 species that were recaptured, only 8 were observed in both HCC and LCC. Given the low recapture rate, this species distribution could either result from sampling effects or suggest that moth responses to urban landscape structure differ between species. From a "conservation planning" point of view, our results support the use of surrogate approaches to estimate the efficiency of corridors modeled by LCP (Wiens, Hayward, Holthausen, \& Wisdom, 2008). However, the inter-specific variability in responses to landscape connectivity support the recent advances in methods to select surrogate species (Meurant, Gonzalez, Doxa, \& Albert, 2018, Ovaskainen et al., 2019). Assessing functional traits associated with movement behaviors to define "dispersal guilds" (i.e. a group of species similar inter-patch and gap-crossing distances, minimum patch area; Lechner, Sprod, Carter, \& Lefroy, 2017) shall indeed improve surrogate approaches (Diniz et al., 2018).

\section{Generalization across habitats and urban landscapes}

Despite the simple setting of our LCP models, corridors modeled using this method were appropriate considering the different types of vegetation structure (herbaceous and open vegetation for moths or wooded and closed vegetation for birds). We performed LCP analyses in a simple and pragmatic way, to stay close to tools that are available and can be used by landscape planners. For instance, resistance values were based on land cover classification and were taken from the literature and using expert knowledge, both of which are available to them. Urban landscapes are highly fragmented, and artificialized surfaces predominate (Parris, 2016). This contrasted matrix may reduce the number of favorable alternative pathways. Consequently, urban landscapes may correspond better to the LCP assumptions 
than to those of other types such as agricultural landscapes, which are more heterogeneous and where alternative pathways are more numerous. The constraints of urban landscape can thus compensate for the classical criticism of unrealistic biological assumptions such as landscape omniscience and a single optimal path (Coulon et al., 2015; LaPoint et al., 2015), as well as the difficulty associated to the choice of resistance values (Zeller et al., 2012). The efficiency of LCP was demonstrated for two medium-sized cities. Even if urban systems are known to be similar in terms of structures and constraints (Savard, Clergeau \& Mennechez, 2000), each city has its own policy of green spaces management that can influence the structure of urban corridors (mineralization rate, mowing frequency, etc.; Haaland \& Van den Bosch, 2015; Smetana \& Crittenden, 2014). Each city is therefore characterized by different connectivity contexts along an urban gradient. Our results demonstrate that LCPs are relevant tools to build efficient corridors in a wide range of medium-sized cities with different urban landscape structures.

\section{Conclusion}

Simple LCP modeling based on expert knowledge and data from the literature was used to parameterize models for generic species. Both experimental protocols made it possible to characterize individual movements across different connectivity contexts (herbaceous versus wooded habitats). As a result, our study showed that the propensity to move and the intensity of movement of moth and passerine species were facilitated in corridors modeled by LCP analysis. The agreement between the results in different biological models and across cities also underlined the relevance of LCP analysis for planning urban greenways. These corridors were shown to be functional in field trials, confirming that LCP is a relevant tool to support landscape planners in the development and the management of both wooded and grassy green 
infrastructures to favor movement and hence to maintain numerous species in urban environments.

\section{Authors' contributions}

M. Balbi, A. Ernoult, S. Croci, E. Petit and A. Butet conceived the ideas and designed methodology; JP. Caudal, M. Balbi, A. Ernoult and S. Croci conceived and made the 45 moth light traps; M. Balbi, A. Ernoult, R. Georges, S. Croci and A. Butet collected the data; M. Balbi, A. Ernoult, E. Petit and L. Madec analyzed the data; M. Balbi, A. Ernoult, S. Croci wrote the manuscript. All authors contributed critically to the drafts and gave their final approval for publication.

\section{Acknowledgements}

We thank Jean Nabucet (UMR 6554 LETG) for providing habitat maps. We are very grateful to many students who helped collect field data, and to the naturalist association CPIE Chaine des Terrils, our partner in this research project. We thank Daphne Goodfellow: d.goodfellow@free.fr), a native English speaker for the English revision of this manuscript. Financial support was provided by the French Nord-Pas de Calais and Bretagne regions (Corbam project). The fieldwork was conducted in the Zone Atelier Armorique, a Long-Term Ecological Research (LTER) site.

\section{Data availability statement}

Data available via the Dryad Digital Repositor https://doi.org/10.5061/dryad.n02v6wwvz (Balbi, Manon et al. 2020), 


\section{References}

Abrahms, B., Sawyer, S. C., Jordan, N. R., McNutt, J. W., Wilson, A. M., \& Brashares, J. S. (2017). Does wildlife resource selection accurately inform corridor conservation? Journal of Applied Ecology, 54(2), 412-422. doi: 10.1111/1365-2664.12714

Adriaensen, F., Chardon, J. P., De Blust, G., Swinnen, E., Villalba, S., Gulinck, H., \& Matthysen, E. (2003). The application of 'least-cost' modelling as a functional landscape model. Landscape and Urban Planning, 64(4), 233-247. doi: $10.1016 / \mathrm{S} 0169-2046(02) 00242-6$

Alison, J., Duffield, S. J., Morecroft, M. D., Marrs, R. H., \& Hodgson, J. A. (2017). Successful restoration of moth abundance and species-richness in grassland created under agri-environment schemes. Biological Conservation, 213, 51-58. doi: 10.1016/j.biocon.2017.07.003

Aronson, M. F., Lepczyk, C. A., Evans, K. L., Goddard, M. A., Lerman, S. B., MacIvor, J. S., ... Vargo, T. (2017). Biodiversity in the city: key challenges for urban green space management. Frontiers in Ecology and the Environment, 15(4), 189-196. doi: 10.1002/fee. 1480

Aronson, M. F., Sorte, F. A. L., Nilon, C. H., Katti, M., Goddard, M. A., Lepczyk, C. A., ... Winter, M. (2014). A global analysis of the impacts of urbanization on bird and plant diversity reveals key anthropogenic drivers. Proc. R. Soc. B, 281(1780), 20133330. doi: $10.1098 / \mathrm{rspb} .2013 .3330$

Balbi, M., Ernoult, A., Poli, P., Madec, L., Guiller, A., Martin, M.-C., ... Petit, E. J. (2018). Functional connectivity in replicated urban landscapes in the land snail ( Cornu aspersum ). Molecular Ecology, 27(6), 1357-1370. doi: 10.1111/mec.14521

Balbi, M., Petit, E. J., Croci, S., Nabucet, J., Georges, R., Madec, L., \& Ernoult, A. (2019). Ecological relevance of least-cost path analysis: An easy implementation method for 
landscape urban planning. Journal of Environmental Management, 244, 61-68. doi: 10.1016/j.jenvman.2019.04.124

Balbi, M., Croci, S., Petit, E. J., Butet, A., Georges, R., Madec, L., Caudal, J.P., \& Ernoult, A. (2020), Data from: Least-cost path analysis for urban greenways planning: a test with moths and birds across two habitats and two cities, Dryad, Dataset, https://doi.org/10.5061/dryad.n02v6wwvz

Bartoń, K. (2020). MuMIn: Multi-Model Inference. R package version 1.43.17. https://CRAN.R-project.org/package=MuMIn

Bates, A. J., Sadler, J. P., Grundy, D., Lowe, N., Davis, G., Baker, D., ... Young, H. (2014). Garden and landscape-scale correlates of moths of differing conservation status: significant effects of urbanization and habitat diversity. PLOS ONE, 9(1), e86925. doi: 10.1371/journal.pone.0086925

Bélisle, M. (2005). Measuring landscape connectivity: the challenge of behavioral landscape ecology. Ecology, 86(8), 1988-1995. doi: 10.1890/04-0923

Benjamini, Y., \& Hochberg, Y. (1995). Controlling the false discovery rate: a practical and powerful approach to multiple testing. Journal of the Royal Statistical Society Series $B, 57,289-300$. doi: 10.1111/j.2517-6161.1995.tb02031.x

Betts, M. G., Gutzwiller, K. J., Smith, M. J., Robinson, W. D., \& Hadley, A. S. (2015). Improving inferences about functional connectivity from animal translocation experiments. Landscape Ecology, 30(4), 585-593. doi: 10.1007/s10980-015-0156

Betzholtz, P. E., Pettersson, L. B., Ryrholm, Nils. \& Franzén, M. (2013). With that diet, you will go far: trait-based analysis reveals a link between rapid range expansion and a nitrogen-favoured diet. Proceedings of the Royal Society B, (280). doi: 10.1098/rspb.2012.2305 
Bond, M. L., Bradley, C. M., Kiffner, C., Morrison, T. A., \& Lee, D. E. (2017). A multimethod approach to delineate and validate migratory corridors. Landscape Ecology, 1-17. doi: 10.1007/s10980-017-0537-4

Bowler, D. E., Buyung-Ali, L., Knight, T. M., \& Pullin, A. S. (2010). Urban greening to cool towns and cities: A systematic review of the empirical evidence. Landscape and Urban Planning, 97(3), 147-155. doi: 10.1016/j.landurbplan.2010.05.006

Braaker, S., Moretti, M., Boesch, R., Ghazoul, J., Obrist, M. K., \& Bontadina, F. (2014). Assessing habitat connectivity for ground-dwelling animals in an urban environment. Ecological Applications, 24(7), 1583-1595. doi: 10.1890/13-1088.1

Breckheimer, I., Haddad, N. M., Morris, W. F., Trainor, A. M., Fields, W. R., Jobe, R. T., ... Walters, J. R. (2014). Defining and Evaluating the Umbrella Species Concept for Conserving and Restoring Landscape Connectivity. Conservation Biology, 28(6), 1584-1593. doi: 10.1111/cobi.12362

Castellón, T. D., \& Sieving, K. E. (2006). An experimental test of matrix permeability and corridor use by an endemic understory bird. Conservation Biology, 20(1), 135-145. doi: 10.1111/j.1523-1739.2006.00332.x

Coulon, A., Aben, J., Palmer, S. C. F., Stevens, V. M., Callens, T., Strubbe, D., ... Travis, J. M. J. (2015). A stochastic movement simulator improves estimates of landscape connectivity. Ecology, 96(8), 2203-2213. doi: 10.1890/14-1690.1

Creegan, H. P., \& Osborne, P. E. (2005). Gap-crossing decisions of woodland songbirds in Scotland: an experimental approach. Journal of Applied Ecology, 42(4), 678-687. doi: 10.1111/j.1365-2664.2005.01057.x

Croci, S., Butet, A., \& Clergeau, P. (2008). Does urbanization filter birds on the basis of their biological traits?. The Condor, 110(2), 223-240. doi: 10.1525/cond.2008.8409 
Diniz, M. F., Machado, R. B., Bispo, A. A., \& De M. Júnior, P. (2018). Can we face different types of storms under the same umbrella? Efficiency and consistency of connectivity umbrellas across different patchy landscape patterns. Landscape Ecology, 33(11), 1911-1923. doi: 10.1007/s10980-018-0720-2

Evans, B. S., Kilpatrick, A. M., Hurlbert, A. H. \& Marra, P. P. (2017). Dispersal in the Urban Matrix: Assessing the Influence of Landscape Permeability on the Settlement Patterns of Breeding Songbirds. Frontiers in Ecology and Evolution, 5, 63. doi: 10.3389/fevo.2017.00063

Fagan, W. F., \& Calabrese, J. M. (2006). Quantifying connectivity: balancing metric performance with data requirements. In K. R. Crooks and M. Sanjayan (Eds.), Connectivity conservation (pp. 297-317). Cambridge, United Kingdom: Cambridge University Press.

Foltête, J.-C., Clauzel, C., \& Vuidel, G. (2012). A software tool dedicated to the modelling of landscape networks. Environmental Modelling \& Software, 38, 316-327. doi: 10.1016/j.envsoft.2012.07.002

Forman, R. T. T. (2014). Urban Ecology: Science of Cities. Cambridge University Press.

Fox, R., Oliver, T. H., Harrower, C., Parsons, M.S. Thomas, C. D., \& Roy, D. B. (2014). Long-term changes to the frequency of occurrence of British moths are consistent with opposing and synergistic effects of climate and land-use changes. Journal of Applied Ecology, 51(4), 949-957. doi: 10.1111/1365-2664.12256

Frank, K. D. (2006). Effects of artificial night lighting on moths. In C. Rich \& T. Longcore, Ecological Consequences of Artificial Night Lighting (Island Press). Washington DC.

Galipaud, M., Gillingham, M. A. F., David, M., \& Dechaume-Moncharmont, F.-X. (2014). Ecologists overestimate the importance of predictor variables in model averaging: a plea for cautious interpretations. Methods in Ecology and Evolution, 5, 983-991. 
Gilbert-Norton, L., Wilson, R., Stevens, J. R., \& Beard, K. H. (2010). A meta-analytic review of corridor effectiveness. Conservation Biology, 24(3), 660-668.

Grimm, N. B., Faeth, S. H., Golubiewski, N. E., Redman, C. L., Wu, J., Bai, X., \& Briggs, J. M. (2008). Global change and the ecology of cities. Science, 319(5864), 756-760. doi: 10.1126/science. 1150195

Grueber, C. E., Nakagawa, S., Laws, R. J., \& Jamieson, I.G. (2011). Multimodel inference in ecology and evolution: challenges and solutions. Journal of Evolutionary Biology, 24, 699-711. Haaland, C., \& Van den Bosch, C. K. (2015). Challenges and strategies for urban green-space planning in cities undergoing densification: A review. Urban Forestry \& Urban Greening, 14(4), 760-771. doi: 10.1016/j.ufug.2015.07.009

Knowlton, J. L., \& Graham, C. H. (2010). Using behavioral landscape ecology to predict species' responses to land-use and climate change. Biological Conservation, 143(6), 1342-1354. doi: 10.1016/j.biocon.2010.03.011

LaPoint, S., Balkenhol, N., Hale, J., Sadler, J., \& van der Ree, R. (2015). Ecological connectivity research in urban areas. Functional Ecology, 29(7), 868-878. doi: $10.1111 / 1365-2435.12489$

LaPoint, S., Gallery, P., Wikelski, M., \& Kays, R. (2013). Animal behavior, cost-based corridor models, and real corridors. Landscape Ecology, 28(8), 1615-1630. doi: $10.1007 / \mathrm{s} 10980-013-9910-0$

Lechner, A. M., Sprod, D., Carter, O., \& Lefroy, E. C. (2017). Characterising landscape connectivity for conservation planning using a dispersal guild approach. Landscape Ecology, 32(1), 99-113. doi: 10.1007/s10980-016-0431-5

Lenth R, Singmann, H., Love, J., Buerkner, P., Herve, M. (2018). emmeans: estimated marginal means, aka least-squares means. R package v.1.2.3. https://github.com/rvlenth/emmeans 
McClure, M. L., Hansen, A. J., \& Inman, R. M. (2016). Connecting models to movements: testing connectivity model predictions against empirical migration and dispersal data. Landscape Ecology, 1-14. doi: 10.1007/s 10980-016-0347-0

Macgregor, C.J., Evans, D. M. Fox, R., Pocock M.J. O. (2017). The dark side of street lighting: impacts on moths and evidence for the disruption of nocturnal pollen transport. Global Change Biology, 23, 697-707. doi: 10.1111/gcb.13371

McRae, B. H., Dickson, B. G., Keitt, T. H., \& Shah, V. B. (2008). Using circuit theory to model connectivity in ecology, evolution, and conservation. Ecology, 89(10), 27122724. doi: 10.1890/07-1861.1

Merckx, T. \& Van Dyck, H. (2007). Habitat fragmentation affects habitat-finding ability of the speckled wood butterfly, Pararge aegeria L. Animal Behaviour, (74), 1029-1037. doi: 10.1016/j.anbehav.2006.12.020

Merckx, T., Feber, R. E., Dulieu, R. L., Townsend, M. C., Parsons, M. S., Bourn, N. A., ... \& Macdonald, D. W. (2009). Effect of field margins on moths depends on species mobility: field-based evidence for landscape-scale conservation. Agriculture, Ecosystems \& Environment, 129(1-3), 302-309. doi: 10.1016/j.agee.2008.10.004 Merckx, T., Feber, R. E., Parsons, M. S., Bourn, N. A., Townsend, M. C., Riordan, P., \& Macdonald, D. W. (2010). Habitat preference and mobility of Polia bombycina: are non-tailored agri-environment schemes any good for a rare and localised species?. Journal of Insect Conservation, 14(5), 499-510. doi: 10.1007/s10841-010-9279-1

Merckx, T., Feber, R. E., Mclaughlan, C., Bourn, N. A. D., Parsons, M. S., Townsend, M. C., ... Macdonald, D. W. (2010). Shelter benefits less mobile moth species: The fieldscale effect of hedgerow trees. Agriculture, Ecosystems \& Environment, 138(3-4), 147-151. doi: 10.1016/j.agee.2010.04.010 
Merckx, T. \& Slade, E. M. (2014). Macro-moth families differ in their attraction to light: implications for light-trap monitoring programmes. Insect Conservation and Diversity, 7, 453-461. doi: 10.1111/icad.12068

Merckx, T., Souffreau, C., Kaiser, A., Baardsen, L. F., Backeljau, T., Bonte, D., ... Van Dyck, H. (2018). Body-size shifts in aquatic and terrestrial urban communities. Nature, 558, 113-116. doi:10.1038/s41586-018-0140-0

Merckx, T., \& Van Dyck, H. (2019). Urbanization-driven homogenization is more pronounced and happens at wider spatial scales in nocturnal and mobile flying insects. Global Ecology and Biogeography, 28, 1440-1455. doi 10.1111/geb.12969

Meurant, M., Gonzalez, A., Doxa, A., \& Albert, C. H. (2018). Selecting surrogate species for connectivity conservation. Biological Conservation, 227, 326-334. doi: 10.1016/j.biocon.2018.09.028

Murgui, E., \& Hedblom, M. (Eds.). (2017). Ecology and Conservation of Birds in Urban Environments. Springer.

New, T. R. (2004). Moths (Insecta: Lepidoptera) and conservation: background and perspective. Journal Of Insect Conservation, 8(2-3), 79-94. doi: 10.1007/s10841-004$1329-0$

New, T. R. (2015). Landscape Connectivity for Urban Insects. In Insect Conservation and Urban Environments (pp. 203-212). Retrieved from http://link.springer.com/chapter/10.1007/978-3-319-21224-1_10

Ovaskainen, O., Ramos, D. L., Slade, E. M., Merckx, T., Tikhonov, G., Pennanen, J., ... \& Morales, J. M. (2019). Joint species movement modeling: how do traits influence movements? Ecology, 100(4), e02622. doi: 10.1002/ecy.2622 
Palmer, S. C. F., Coulon, A., \& Travis, J. M. J. (2011). Introducing a 'stochastic movement simulator' for estimating habitat connectivity. Methods in Ecology and Evolution, 2(3), 258-268. doi: 10.1111/j.2041-210X.2010.00073.x

Parris, K. M. (2016). Ecology of Urban Environments. John Wiley \& Sons.

Pe'er, G., Saltz, D., Thulke, H. H., Motro, U. (2004). Response to topography in a hilltopping butterfly and implications for modelling nonrandom dispersal, Animal Behaviour (68), 825-839, doi: 10.1016/j.anbehav.2004.02.006.

Potts, J. R., \& Lewis, M. A. (2014). How do animal territories form and change? Lessons from 20 years of mechanistic modelling. Proceedings of the Royal Society of London B: Biological Sciences, 281(1784), 20140231. doi: 10.1098/rspb.2014.0231

Richardson, J. L., Brady, S. P., Wang, I. J., \& Spear, S. F. (2016). Navigating the pitfalls and promise of landscape genetics. Molecular Ecology, 25(4), 849-863. doi:

$10.1111 / \mathrm{mec} .13527$

Savard, J.-P. L., Clergeau, P., \& Mennechez, G. (2000). Biodiversity concepts and urban ecosystems. Landscape and Urban Planning, 48(3-4), 131-142. doi: 10.1016/S01692046(00)00037-2

Sawyer, S. C., Epps, C. W., \& Brashares, J. S. (2011). Placing linkages among fragmented habitats: do least-cost models reflect how animals use landscapes? Journal of Applied Ecology, 48(3), 668-678. doi: 10.1111/j.1365-2664.2011.01970.x

Scoble, M. J. (1992). The lepidoptera: form, function, and diversity. Oxford University Press.

Shimazaki, A., Yamaura, Y., Senzaki, M., Yabuhara, Y., Akasaka, T., \& Nakamura, F. (2016). Urban permeability for birds: An approach combining mobbing-call experiments and circuit theory. Urban Forestry \& Urban Greening, 19, 167-175. doi: 10.1016/j.ufug.2016.06.024 
Slade, E. M., Merckx, T., Riutta, T., Bebber, D. P., Redhead, D., Riordan, P., \& Macdonald, D. W. (2013). Life-history traits and landscape characteristics predict macro-moth responses to forest fragmentation. Ecology, 94(7), 1519-1530. doi: 10.1890/12-1366.1

Smetana, S. M., \& Crittenden, J. C. (2014). Sustainable plants in urban parks: A life cycle analysis of traditional and alternative lawns in Georgia, USA. Landscape and Urban Planning, 122, 140-151. doi: 10.1016/j.landurbplan.2013.11.011

St Clair, C. C. (2003). Comparative permeability of roads, rivers, and meadows to songbirds in Banff National Park. Conservation Biology, 17(4), 1151-1160. doi: 10.1046/j.15231739.2003.02156.x

St-Louis, V., Forester, J. D., Pelletier, D., Bélisle, M., Desrochers, A., Rayfield, B., ... Cardille, J. A. (2014). Circuit theory emphasizes the importance of edge-crossing decisions in dispersal-scale movements of a forest passerine. Landscape Ecology, 29(5), 831-841. doi: 10.1007/s10980-014-0019-x

Šumpich, J., \& Konvička, M. (2012). Moths and management of a grassland reserve: regular mowing and temporary abandonment support different species. Biologia, 67(5). doi: $10.2478 / \mathrm{s} 11756-012-0095-9$

Taylor, P. D., Fahrig, L., Henein, K., \& Merriam, G. (1993). Connectivity is a vital element of landscape structure. Oikos, 68(3), 571-573. doi: 10.2307/3544927

Tremblay, M. A., \& St Clair, C. C. (2011). Permeability of a heterogeneous urban landscape to the movements of forest songbirds. Journal of Applied Ecology, 48(3), 679-688. doi: 10.1111/j.1365-2664.2011.01978.x

Turchin, P. (1998). Quantitative analysis of movement: measuring and modeling population redistribution in animals and plants (Vol. 1). Retrieved from http://library.wur.nl/WebQuery/clc/950885 
Wiens, J. A., Hayward, G. D., Holthausen, R. S., \& Wisdom, M. J. (2008). Using Surrogate Species and Groups for Conservation Planning and Management. BioScience, 58(3), 241-252. doi: 10.1641/B580310

Zeller, K. A., McGarigal, K., \& Whiteley, A. R. (2012). Estimating landscape resistance to movement: a review. Landscape Ecology, 27(6), 777-797. doi: 10.1007/s10980-012$9737-0$

List of figures

Figure 1.

A. Geographic location of the study areas (Rennes, north-western France, and Lens, northern France). The experimental design was similar for the two cities and is illustrated only for Rennes. B and C. Maps of resistance values of the study area (Rennes), location of habitat patches and least-cost paths (LCP). B. Mark-release-recapture (MRR) system for moths. C. Starting points of playback trial systems for passerine birds. D. Example of positions of traps in a habitat patch in highly connecting contexts (HCC) and less connecting contexts (LCC). E. Example of the position of playback trials in highly connecting contexts (HCC) and less connecting contexts (LCC).

\section{Figure 2.}

Mean number of recaptures of moths per satellite area in each connectivity context. HCC: highly connecting contexts. LCC: less connecting contexts. Error bars are 95\% CI from nonparametric bootstrap. Significance of context factor retrieved from the model averaging analysis: the $95 \%$ confidence interval of the effect size excludes 0 (Appendix S12).

\section{Figure 3.}

Predicted maximum distance reached during trials linked with passerine species and connectivity contexts. HCC: highly connecting contexts. LCC: less connecting contexts. The number of individuals per species is given under the $\mathrm{x}$-axis. Error bars are 95\% CI. Significance of the post-hoc interaction analysis, $* *: \mathrm{p}<0.01 ; * * *: \mathrm{p}<0.001$.

\section{Figure 4.}

Predicted response time (in seconds) to playback recall trials linked to trial distance and connectivity context. HCC: highly connecting contexts. LCC: less connecting contexts. Error bars are $95 \%$ CI. Significance of the post-hoc interaction analysis, **: $p<0.01$. 
Figure 1
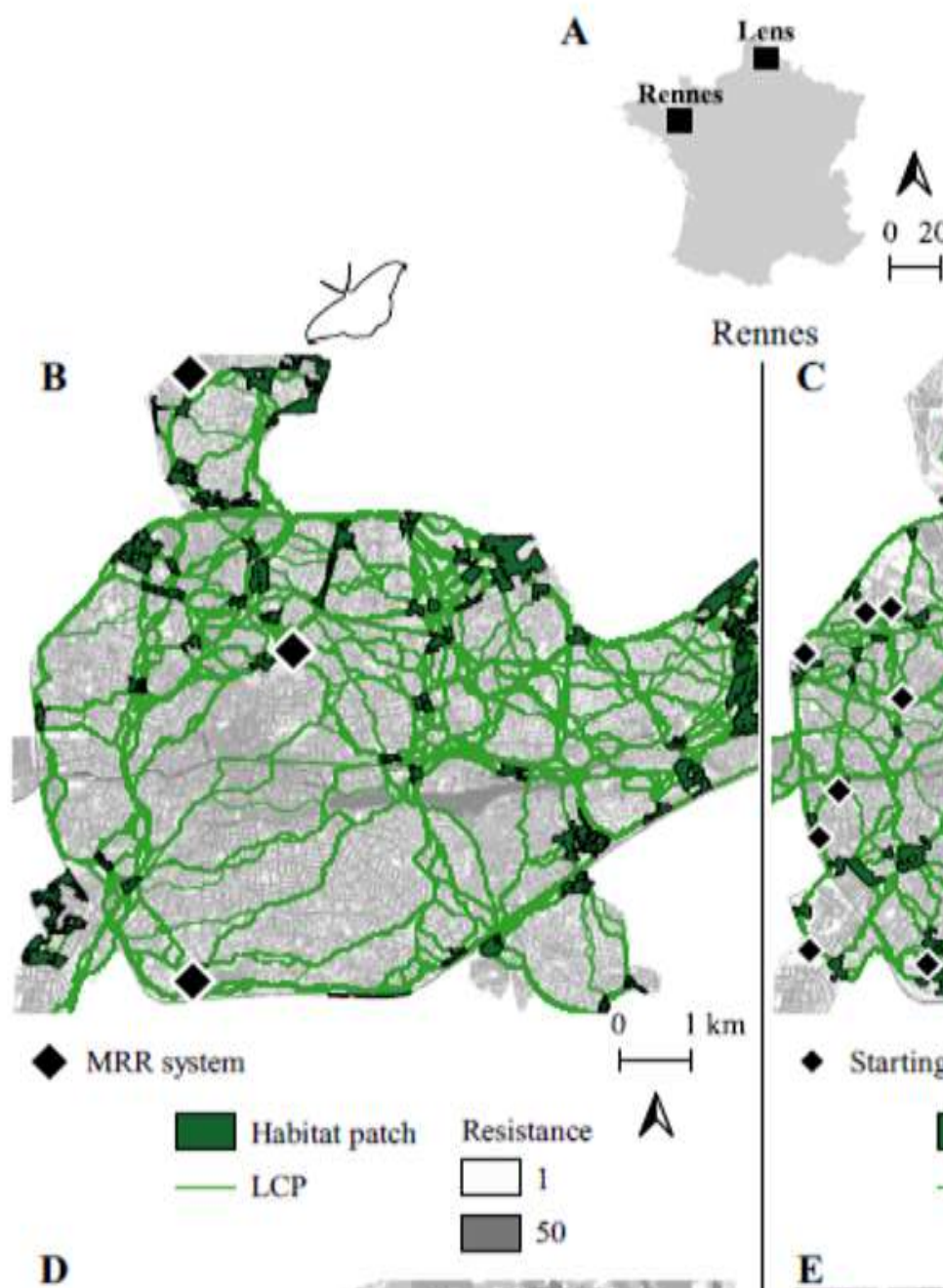

\section{$0200 \mathrm{~km}$}

$\square$



D

E
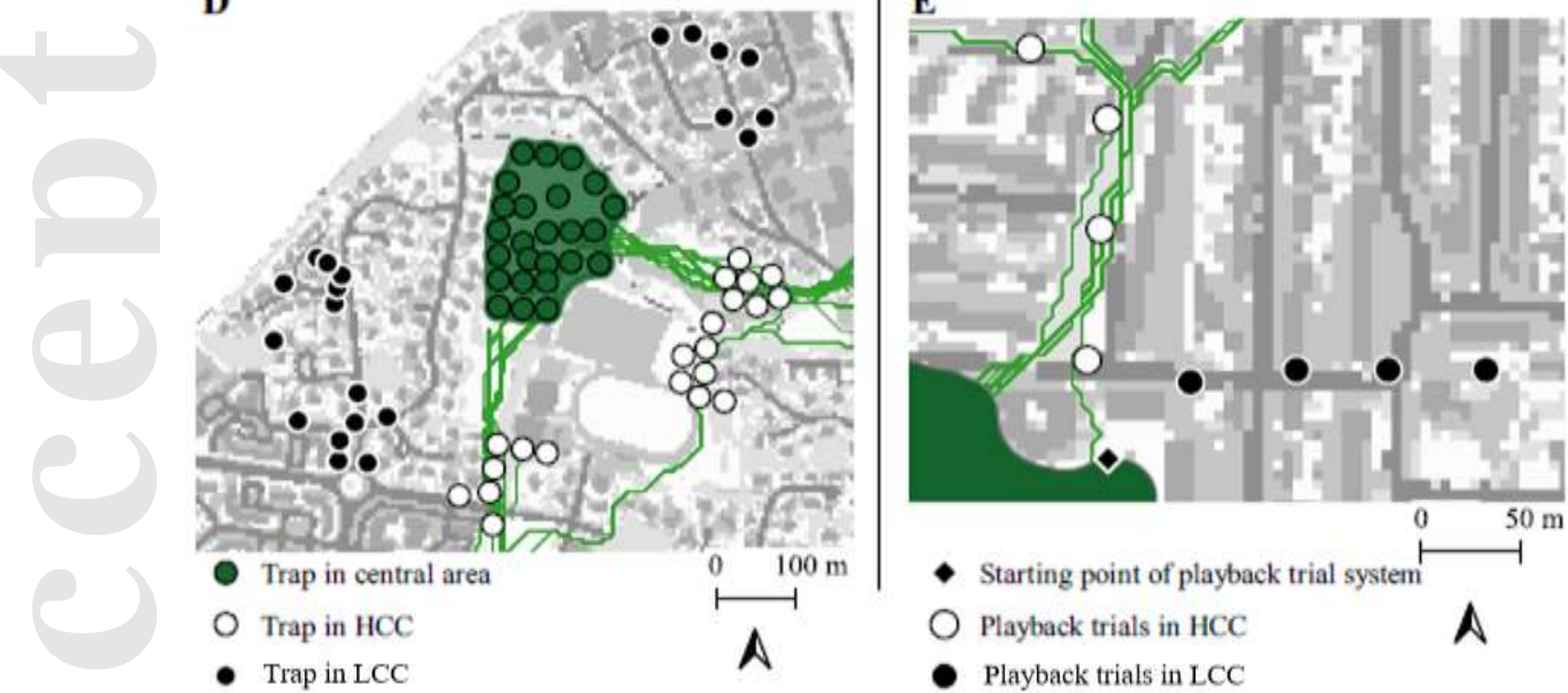
Figure 2



Connectivity context 
Figure 3




Figure 4

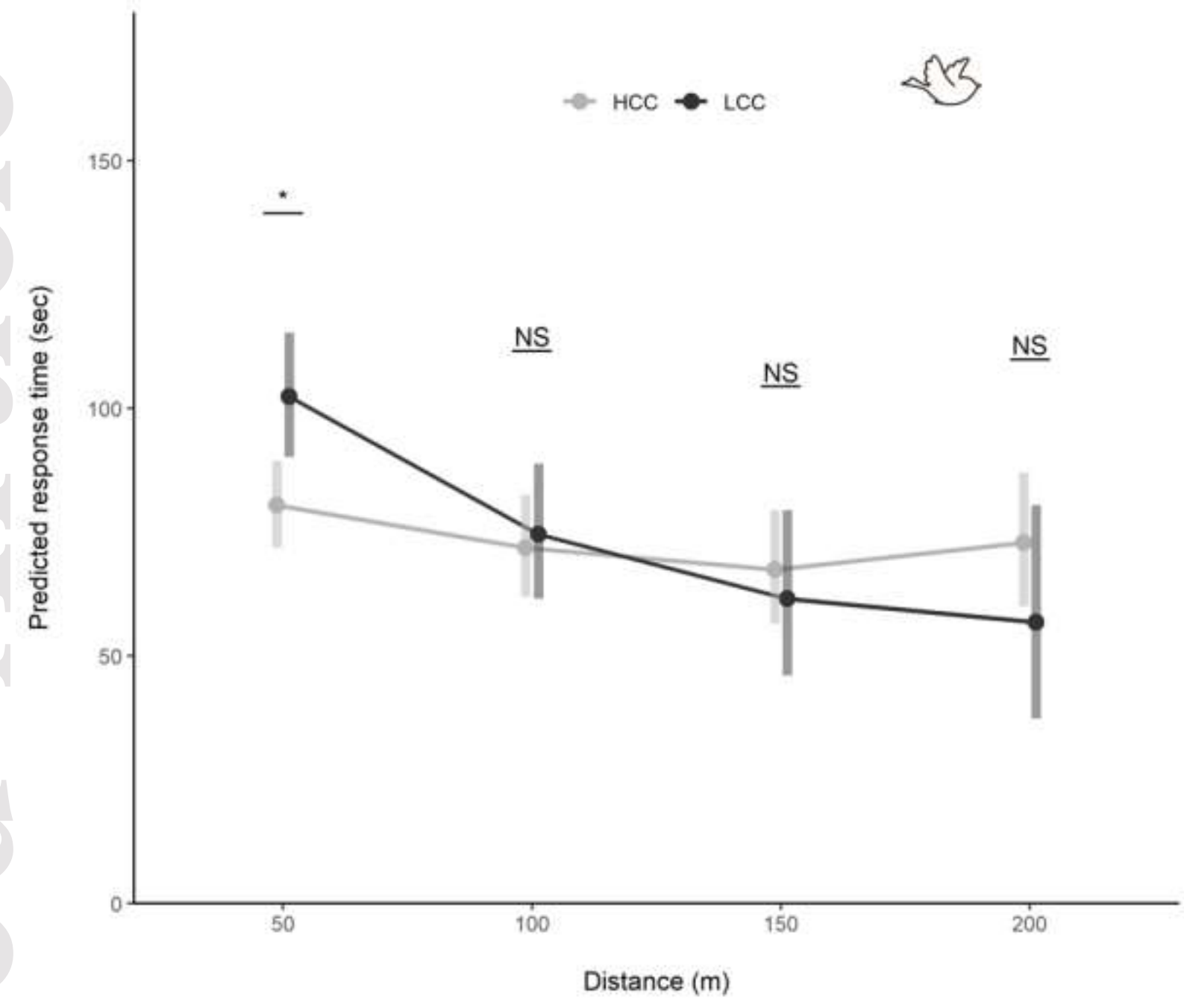

